\title{
O papel dos movimentos sociais na geopolítica contemporânea: uma análise das comunidades de pescadores do litoral cearense e suas interações com o Estado
}

\author{
The social movements role on the current geopolitics: \\ an analysis of the coastal fishing community of Ceará State and \\ its interactions with the Brazilian State
}

\author{
El papel de los movimientos sociales en la geopolítica \\ contemporánea: un análisis de las comunidades de pescadores \\ de Ceará y sus interacciones con el Estado brasileño
}

Helvisney dos Reis Cardoso neyrcd@gmail.com Universidade de Brasília

Lucas Guimarães Grisolia lucas.grisolia@gmail.com Universidade de Brasília

Wânessa Marques Silva wanessamarq@gmail.com

Universidade de Brasília

\begin{abstract}
Resumo: Em uma análise geopolítica, pretende-se mostrar as relações de poder entre dois atores sociais, o Movimento Nacional dos Pescadores e o Estado brasileiro. Para melhor compreendê-los, apresentamos o conceito de território como diferentes formas de apropriação pelos atores, o histórico do movimento e suas reivindicações, além das políticas estatais para o setor pesqueiro. Foi observado um esforço para articular as comunidades tradicionais pesqueiras com o intuito de buscarem seus interesses junto ao Estado com maior eficiência em contraponto às políticas de desenvolvimento do setor pesqueiro que beneficiavam apenas produtores industriais do setor. Nossos resultados sugerem que uma política do setor pesqueiro falha proporciona o surgimento de um movimento social muito importante para a defesa dos interesses das comunidades tradicionais no Brasil. Dessa forma, os pescadores tradicionais mostram-se bem articulados e com voz ativa nas tomadas de decisão que lhes dizem respeito.
\end{abstract}

Palavras-chave: Geopolítica. Movimentos Sociais. Pesca. Brasil.

Abstract: Through a geopolitics analysis, we intend to show the power relations between two social actors, the National Fishermen Movement and the Brazilian State. In order for a better understanding of those mentioned, we present the concept of territory as different forms appropriated by these actors, the history of the movement and their claims, besides the state policies to the fishing sector. We observed an effort 
to articulate the traditional fishing communities toward to more efficiently pursuit their interests regarding the state, in contrast to the development policies in the fishing sector which benefited only the industrial fishing sector. Our results suggest that a state's policy to the fishing sector fails to provide the development of a social movement that is very important for preserving the traditional Brazilian communities. Therefore, traditional fishermen show themselves to be very articulated and with an active voice on the decision-making process that concerns them.

Keywords: Geopolitics. Social Movements. Fishery. Brazil.

Resumen: En un análisis geopolítico se pretende mostrar las relaciones de poder entre dos actores sociales, el Movimiento Nacional de Pescadores y el estado brasileño. Para mejor entender todo esto, presentamos el concepto de territorio como las diferentes formas de apropiación por los actores, la historia del movimiento y sus demandas, además de las políticas estatales para el sector pesquero. Fue observado un esfuerzo por articular las comunidades pesqueras tradicionales con el fin de la búsqueda por sus intereses con el Estado de manera más eficiente en comparación con el desarrollo político del sector de la pesca que benefició apenas a los productores del sector industrial. Nuestros resultados sugieren que un fracaso de la política en el sector de la pesca proporciona el surgimiento de un movimiento social muy importante para la defensa de los intereses de las comunidades tradicionales de Brasil. De este modo, los pescadores tradicionales se presentan bien articulados y con voz activa en las decisiones que les afectan.

Palabras claves: Geopolitica. Movimientos sociales. Pesca. Brasil.

\section{INTRODUÇÃO}

Durante muito tempo, a Geografia Política - hoje chamada de clássica - restringiu-se a estudar as relações de poder que se davam entre estados e determinados territórios. Contudo, com o passar dos anos, esse campo de estudo não pôde ignorar a emergência de novos atores sociais que começaram a interagir com o Estado, como os movimentos sociais, as organizações internacionais, os blocos econômicos, as empresas privadas, as organizações não governamentais etc. Esses novos agentes foram de grande contribuição para a ampliação das questões abordadas pela Geopolítica, uma vez que as relações de poder sobre determinados territórios já não eram mais exclusividade dos Estados, passando a ocorrer também entre diferentes grupos sociais.

Nesse sentido, pode-se destacar a atuação dos movimentos sociais como um dos importantes agentes que ajudaram a Geografia Política a tomar novos rumos. Os movimentos sociais - que para Maria Gohn são "ações coletivas de caráter sócio-político e cultural que viabilizam distintas formas da população se organizar" (GOHN, 2003, p.13) - começaram a obter uma maior organização nas sociedades pós-industriais. Entretanto, foi somente após a segunda metade do século XX que a Geopolítica passou a abordá-los nos seus estudos, pois, foi nesta época que esses movimentos conseguiram aumentar 
significativamente sua participação nas tomadas de decisão dentro das grandes sociedades e modificar as relações de poder que dominavam o meio em que estavam inseridos.

Contudo, em fins dos anos de 1980 e meados dos anos de 1990, no Brasil e na América Latina, houve certa desmobilização dos movimentos sociais que só voltaram a ter uma maior ação na virada para o século XXI. Os chamados novos movimentos sociais (NMS) adquiriram características que foram decisivas para a obtenção de uma atuação mais presente e objetiva. Estes deixaram de lado padrões hierárquicos, assim como padrões classistas, passando a compreender temas difusos e buscar distintas formas de autonomia, como autodeterminação, planejamento estratégico, flexibilidade, universalização de demandas particulares e capacitação de pessoal. Além disso, criaram identidades coletivas, que estão ligadas à definição de seus membros, como eles vêem a si mesmos e o seu relacionamento com o ambiente em que estão inseridos. Essa criação de uma identidade que englobe uma coletividade não se caracteriza como um processo linear, mas sim como um processo de interação, negociação e de oposição de diferentes orientações, o que acaba por gerar grupos mais conscientes de suas realidades e possibilidades (GOHN, 2000, 2003).

Os NMS também pararam de dar as costas para o Estado. A política feita pelo Estado passa a ser vista como uma dimensão da vida social que abarca todas as práticas sociais. Assim, a participação ativa em questões políticas ajudou na criação de novos canais de comunicação entre sociedade e Estado e contribuiu para a institucionalização de espaços públicos importantes, como os diferentes conselhos criados nas esferas municipal, estadual e nacional. Outra atual propriedade dos NMS é sua ação por meio de redes de interação que acontecem graças ao desenvolvimento de sociedades globalizadas e informatizadas. Essas redes possibilitam uma maior articulação entre os movimentos sociais e suas demandas, gerando resultados mais amplos e consistentes (GOHN, 2000, 2003).

A utilização de novos meios de comunicação para o "agir comunicativo" também foi imprescindível para o desenvolvimento das novas características dos movimentos. Desse modo, os papéis da ação comunicativa e da mídia para a efetiva atuação do NMS são salientados por diversos autores, como Habermas, um dos que ligaram a teoria do discurso com a ação dos movimentos sociais. Este autor acredita que na em medida que os atores se entendem dentro das estruturas de cultura, sociedade e personalidade do "mundo vivido" por intermédio de processos comunicativos, passam a partilhar uma tradição cultural que se reflete na formação de uma identidade coletiva - na qual os movimentos sociais são fundamentais para a produção, sendo a mídia o instrumento que difunde identidades e ações (HABERMAS, 1976, 1981). Neste sentido, os NMS têm potencial para reviver o caráter democrático da esfera pública, pois geram o debate social sobre temas muitas vezes manipulados pelo Estado (GOHN, 2000; MICHILES, 2003).

De forma a abarcar todas essas características, os NMS que surgiram no Brasil ao longo dos últimos anos reivindicam as mais diversas demandas, estando entre elas questões ecológicas e de sustentabilidade. Com os avanços da sociedade contemporânea, tanto científicos como sociais, o ser humano começou a notar que a relação homem-natureza não se restringe apenas à visão modernista, onde o meio natural estaria a 
serviço do progresso humano, mas também que existem outras formas de apropriação deste progresso de forma cultural e simbólica. Deste modo, as comunidades tradicionais, classificadas assim por possuírem uma relação "harmoniosa" com a natureza (VIANNA, 2008), vêm se organizando de forma mais articulada no intuito de lutarem pela preservação ambiental e pelos seus direitos de manutenção do seu modo de vida.

Neste contexto, trazendo uma análise das relações de poder entre atores sociais sobre o território, escolheu-se o movimento dos pescadores do litoral cearense, englobado no Movimento Nacional dos Pescadores (MONAPE), como forma de organização articulada de uma população tradicional (os pescadores artesanais) para traçar o histórico de suas lutas e reivindicações. Além de discorrer a respeito de suas relações com o Estado e com as empresas pesqueiras privadas, atores sociais diretamente ligados às políticas formuladas para o setor pesqueiro. Assim, o litoral será abordado como um espaço social, econômico e político, onde ocorrem as relações de poder, que pode ser apropriado de diversas formas por diferentes atores. E o MONAPE, será abordado como representante de um segmento da sociedade que procura se articular para dialogar com o Estado e reivindicar direitos de apropriação de seu território para reprodução social, econômica e cultural dos pescadores artesanais.

Como referências para o aprofundamento do assunto serão consultados tanto autores europeus da geopolítica clássica, como Ratzel, Kjellén, Mackinder, Haushofer e Spykman, quanto os autores brasileiros que muito contribuíram para as políticas de desenvolvimento e soberania nacional. Ainda serão consultados autores, nacionais e estrangeiros, da geopolítica contemporânea para a melhor compreensão do cenário ao qual se inserem as relações de poder analisadas.

\section{TERRITÓRIO: UM CONCEITO FUNDAMENTAL}

Presente como um dos conceitos fundamentais da Geografia Política, o território é analisado por diversos autores, tanto clássicos quanto contemporâneos, tomando formas de interpretação diferentes ao longo do tempo.

Na Geografia Política clássica, Ratzel interpreta-o como "solo e seus condicionantes físicos (...) uma base concreta, um potencial enfim, cuja eficácia para o desenvolvimento estatal de uma nação ou de um povo dependerá antes de tudo da sua capacidade em transformar essa potencialidade em algo efetivo" (COSTA, 1992, p. 35). Essa visão aborda a temática com certo determinismo onde o Estado, mais favorecido de recursos naturais ou com uma hidrografia casualmente estratégica para navegação, estaria favorecido frente a outros. Entretanto, caberia ao povo e sua forma de organização no território o modo com o qual esses recursos seriam utilizados. Posteriormente, o militar e geógrafo político Halford Mackinder (1904) apresenta visão similar quando discorre a respeito da rivalidade entre potências marítimas versus potencias terrestres e desenvolve a teoria do Heartland, na qual apresenta a região das estepes siberianas na Rússia como área pivô inacessível ao assédio do poder marítimo por ser a região de maior extensão em planícies 
e cercada por cadeias montanhosas. Portanto, nota-se claramente a relação do território com o poder como forma de dominação jurídico-política por meio da delimitação de fronteiras. No entanto, as formas de interpretação desse conceito mostram-se mais abrangentes na contemporaneidade.

Segundo Haesbaert (2004) território, em qualquer acepção, tem a ver com poder, mas não apenas ao tradicional "poder político". Ele diz respeito tanto ao poder no sentido mais concreto, de dominação, quanto ao poder no sentido mais simbólico, de apropriação. Nesse caso, o poder de dominação denota o sentido de propriedade, concretude, valor de troca. Já o poder de apropriação traz o sentido de possessão, carregando um valor muito mais simbólico, valor de uso. Deste modo, o território mostra-se múltiplo, permeado por formas de apropriação e dominação, sendo assim, a forma mais presente na sociedade capitalista hegemônica. Nesse âmbito, ele se apresenta relacionado com a multiplicidade de poderes dos atores envolvidos nele incorporados. Portanto, o território é ao mesmo tempo funcional e simbólico. Funcional no que diz respeito a exercer uma função - por exemplo, oferecer de abrigo ou recurso - e simbólico porque produz significados variados de acordo com a sociedade.

Sendo assim, será nessa visão contemporânea que se discorrerá a respeito do litoral, território apropriado de diversas maneiras por inúmeros atores e tendo significados variados ao longo do tempo.

\section{LITORAL: TERRITÓRIO DOS PESCADORES ARTESANAIS}

O litoral, em tempos passados, quando a grande vastidão azul era algo intransponível para o homem, guardava o desconhecido. Povoava o imaginário das pessoas com mitos e lendas sobre o que existia após a rebentação das ondas, demonstrando que mesmo sem ter sido percorrido pelo homem, já era território simbólico. Na Europa, na época das grandes navegações, o litoral representava a chegada de mercadorias e pessoas pelos portos, a ameaça de invasão pirata ou inimiga e fonte de recursos pesqueiros e de sal. Numa sociedade fortemente permeada pelos valores cristãos, o mar era o local de morada das criaturas não desejadas por Deus. Portanto, nas praias só habitavam aqueles que realizavam a atividade da pesca.

Quando o homem toma conhecimento do território marítimo, por meio do desenvolvimento de técnicas, começa então a disputa sobre ele, visto que a sociedade se encontrava em plena expansão de mercados e o domínio nos mares passava a ser questão de soberania nacional para alguns estados. Dessa forma, a relação da sociedade com o litoral se torna mais íntima, pois o significado deste se transforma com a mudança na forma de apropriação. Para Mahan (1991), era fundamental a natureza e o grau de envolvimento de toda a população de um país com as atividades marítimas, decorrendo daí as possibilidades concretas de constituição de um poder de fato nessa área.

Para as colônias de pescadores, o litoral é espaço de reprodução do seu modo de vida, ou seja, local onde desenvolvem suas atividades econômicas e socioculturais. 
A principal atividade dessas comunidades é a pesca, por meio desta o pescador retira sua alimentação e seu produto de comercialização. A territorialidade desse povo está intimamente ligada às técnicas de pesca utilizadas. O pescador que possui uma traineira (barco usado para pesca de sardinha) se desloca em busca dos cardumes de sardinha, portanto, possui um território marítimo extenso onde conhece os melhores pontos de captura do pescado. Já o pescador que pratica a pesca de cerco, técnica que consiste na instalação de uma rede em determinado ponto no mar que só se retira dias depois, não necessita de ir ao mar todos os dias, portanto, tem tempo de se dedicar à outra atividade no litoral (a agricultura, por exemplo). Nota-se que atividade de pesca artesanal consiste no conhecimento do ambiente físico do local (vento, pontos de pesca, marés e ciclo de reprodução das espécies) e nas relações sociais entre pescadores e comunidades. Segundo Vianna (2008), as praias são territórios comuns, onde se configuram as relações sociais. A retirada dos barcos da água, o encontro de manhã cedo para mais um dia pesca, as celebrações e a informação dos acontecimentos são socializações que se concretizam na praia.

Cardoso (2001) diz que a apropriação do território do pescador é medida pelo nível tecnológico dos instrumentos pesqueiros e, sobretudo pelo conhecimento marítimo que cada grupo constrói e desenvolve na sua atuação frente à natureza. A conservação dos recursos naturais marítimos, então, apresenta-se na forma do pescador se relacionar com o mar, praticando o rodízio de pontos de pesca, não capturando indivíduos jovens e mantendo a qualidade das águas.

Fica claro, então, que o litoral é apropriado de forma simbólica no que se diz respeito às crenças e representações sociais das comunidades, e de forma funcional no âmbito de oferecer recursos pesqueiros. Mostrou-se então que a pesca artesanal é uma atividade coletiva, demandando uma relação de confiança entre os pescadores e um vasto conhecimento do território marítimo.

\section{LITORAL: TERRITÓRIO DO ESTADO}

O litoral, historicamente, sempre mereceu grande atenção do Estado por estar diretamente envolvido com a questão da soberania nacional. Por um lado, merecia toda forma de aparato de defesa contra ataques inimigos, como fortes e fortalezas, e por outro, todo tipo de investimento no comércio marítimo com a construção de portos estrategicamente localizados. Para Mahan (1991), havia uma precedência necessária da marinha mercante em relação à de guerra, de modo que é em função da vocação marítima e do comércio que as nações decidiram ou não por uma marinha de guerra. Portanto, o investimento nos portos brasileiros, pontos nodais do poder marítimo, mostrava-se interessante para a afirmação do país no cenário internacional.

Com o desenvolvimento de outras atividades no litoral, como a pesca e a aquicultura $^{1}$, faz-se necessária a aplicação de leis que ordenem e delimitem o território marítimo

1 Aquicultura é considerada uma atividade multidisciplinar, referente ao cultivo de diversos organismos aquáticos, incluídos neste contexto plantas aquáticas, moluscos, crustáceos e peixes, sendo que a intervenção ou manejo do processo de criação é 
brasileiro. Sendo assim, a forma jurídico-política de apropriação desse espaço pelo Estado se dá na forma de leis e políticas que visam à ordenação das atividades relacionadas ao mar, à delimitação de fronteiras marítimas e à questão da soberania nacional.

Nas bases da legislação federal, Lei N. 8617 (BRASIL, 1993), consta:

Do Mar Territorial

Art. $1^{\circ} \mathrm{O}$ mar territorial brasileiro compreende uma faixa de doze milhas marítima de largura, medidas a partir da linha de baixa-mar do litoral continental e insular, tal como indicada nas cartas náuticas de grande escala, reconhecidas oficialmente no Brasil.

Parágrafo único. Nos locais em que a costa apresente recorte profundos e reentrâncias ou em que exista uma franja de ilhas ao longo da costa na sua proximidade imediata, será adotado o método das linhas de base retas, ligando pontos apropriados, para o traçado da linha de base, a partir da qual será medida a extensão do mar territorial.

Art. $2^{\circ}$ A soberania do Brasil estende-se ao mar territorial, ao espaço aéreo sobrejacente, bem como ao seu leito e subsolo.

Art. $3^{\circ}$ É reconhecido aos navios de todas as nacionalidades o direito de passagem inocente no mar territorial brasileiro.

$\S 1^{\circ} \mathrm{A}$ passagem será considerada inocente desde que não seja prejudicial à paz, à boa ordem ou à segurança do Brasil, devendo ser contínua e rápida.

$\S 2^{\circ}$ A passagem inocente poderá compreender o parar e o fundear, mas apenas na medida em que tais procedimentos constituam incidentes comuns de navegação, sejam impostos por motivos de força ou por dificuldade grave, ou tenham por fim prestar auxílio a pessoas, a navios ou a aeronaves em perigo ou em dificuldade grave.

$\S 3^{\circ}$ Os navios estrangeiros no mar territorial brasileiro estarão sujeitos aos regulamentos estabelecidos pelo Governo brasileiro.

Mostra-se, com exemplo na lei federal, que o Estado necessita de um aparato jurídico para delimitar seu território e ordená-lo da maneira que achar melhor para seus interesses. Assim, nota-se que o território assume caráter multifuncional, pois é concebido de múltiplas formas de apropriação dos atores presentes.

\section{O MOVIMENTO DAS COMUNIDADES TRADICIONAIS DE PESCADORES NO BRASIL}

O mar brasileiro, com 8,5 mil quilômetros de costa e 4,5 milhões de quilômetros quadrados de Zona Econômica Exclusiva, representa quase a metade de todo nosso 
território terrestre. As atividades de pesca (não a coleta ocasional de mariscos e de outros recursos aquáticos da costa, que é uma atividade ainda anterior) provavelmente são mais antigas que a agricultura e pecuária. Apesar disso, milhares de anos mais tarde, a pesca continua desempenhando um papel social e econômico fundamental.

Comunidades pesqueiras, cultura marítima, comunidades humanas marítimas, gentes do mar, comunidades tradicionais de pesca, comunidades costeiras ou, simplesmente, povos do mar, representam no Brasil "um contingente populacional de aproximadamente 800 mil pescadores e pescadoras, envolvendo dois milhões de pessoas que produzem cerca de 55\% da produção pesqueira nacional (CALLOU, 2010, p.45).

Nestas comunidades, existem elementos culturais comuns a todas elas, formadas pelas mesmas influências que serviram para sedimentar as primitivas bases culturais da vida litorânea (MUSSOLINE, 1972, p.293), transcendendo os limites meramente familiares para se converterem em atividade comunitária, estabelecendo toda uma série de interações entre os moradores, unindo-os em cooperação. Dentro desse contexto social, há outros aspectos da cultura, das tradições e costumes que adquirem relevância e robustez, dando ao grupo formado uma identidade única e concisa. No contato com outras culturas contemporâneas, esses povos se hibridizam, "desenvolvendo formas particulares de conhecimento e de organização social para a utilização dos recursos naturais e conservação dos recursos marinhos" (DIEGUES, 1993, p.18).

Mas foi renegando essas culturas tradicionais, na maioria das vezes, que as políticas públicas foram elaboradas historicamente para desenvolver o setor pesqueiro brasileiro. A análise histórica das políticas voltadas para a atividade pesqueira no Brasil demonstra que elas atuam em dois sentidos: estabelecer regulamentações e conceder incentivos à produção. Sendo que a base de sustentação dessas políticas é a exploração econômica dos recursos naturais, a partir da modernização das atividades da pesca.

Entre as intervenções realizadas, duas merecem destaque: a Missão do Cruzador José Bonifácio (1919-1924) e a Superintendência do Desenvolvimento da Pesca (Sudepe) (1962-1989). A primeira diz respeito às intervenções da Marinha de Guerra nas comunidades pesqueiras do litoral, com interesses explicitamente militares, permeados de aspectos sociais e econômicos. No tocante à Sudepe "é conveniente observar que a visão orientadora das suas políticas parte da perspectiva de que a pesca brasileira é 'primitiva e miserável'" (SUDEPE, 1963, p.11), os investimentos da Sudepe se dão, majoritariamente, no setor industrial da pesca por meio de incentivos fiscais, o que vai de encontro com o propósito do órgão governamental que é formular políticas para conceder incentivos à produção industrial pesqueira.

A partir da década de 1960, a atividade pesqueira tomou maior impulso. A política de incentivo à produção pesqueira iniciou-se em 1967 com a promulgação do Decreto-lei 221. Até os anos 1960, a atividade pesqueira no Brasil era predominantemente artesanal e sua produção estava voltada basicamente para atender o mercado interno. A partir de então, por intermédio dessa política de incentivos fiscais à pesca, desenvolveu-se a chamada pesca industrial, voltada preferencialmente, para o mercado externo. Pode-se dizer que nesse ponto surgem as relações de poder analisadas ao longo desse artigo. 
Para Paiva e Paiva, “Os resultados dessas políticas não geraram o desenvolvimento pretendido nem da pesca industrial, nem da pesca artesanal (1967, p.28)”. Ao contrário:

A modernização e os incentivos à industrialização da pesca provocaram a depredação de várias espécies de peixes e crustáceos, comprometendo a vida das comunidades litorâneas. Ao lado disso, os pescadores e pescadoras apontavam problemas graves decorrentes do sobre-esforço de pesca, da especulação imobiliária nas praias e do turismo, que expulsou, e expulsa, sistematicamente, as comunidades pesqueiras dos seus territórios tradicionais. (CALLOU, 2010, p.46).

Em 1989, o governo federal extinguiu a Superintendência do Desenvolvimento da Pesca e suas atribuições e competências passaram a ser desempenhadas pelo Instituto Brasileiro do Meio Ambiente e dos Recursos Naturais Renováveis (Ibama), do Ministério do Meio Ambiente, dos Recursos Hídricos e da Amazônia Legal. Com a criação da Secretaria Especial da Aquicultua e Pesca da Presidência da República (Seap), em 2003, hoje ministério da Pesca e Aquicultura (MPA), o governo reconhece a dívida social do país com a pesca artesanal e elabora um plano estratégico de desenvolvimento sustentável.

Logo, "compondo matematicamente a força de expansão das políticas de um Estado e a resistência que os confrontantes, ou outros, a ela se oponham, resulta uma situação de 'equilíbrio dinâmico'" (BACKHEUSER, 1950, p.149). O equilíbrio dinâmico referido se dá, neste caso, somente com a atuação do Estado como forma de mediador e escopo das preposições de ambas as partes e não como criador de demandas. Os conglomerados privados lutam pelo seu direito de exploração e a população tradicional pelos seus direitos históricos e culturais na forma de sobrevivência e territorialização.

O Estado acaba por atuar como alvo e uma ponte entre os movimentos sociais e o bem almejado, organizando-se e buscando algo que depende do Estado. Por conseguinte, pode-se afirmar que os movimentos sociais existem porque o Estado existe e aquele surge a partir do empoderamento das comunidades locais frente seus confrontantes, advindo do sentimento de politização da coletividade. A dinamicidade desse processo de luta por espaços configura o dilema contemporâneo entre a dicotomia da economia de mercado e a preservação de modos de vida tradicionais. O equilíbrio dinâmico mencionado é, então, artificial.

No intuito de discutir a situação socioambiental e econômica da pesca e da agricultura no Brasil e suas possibilidades de desenvolvimento, a Seap promoveu diversas conferências estaduais e nacionais, mostrando um aspecto inovador em termos de implantação de políticas públicas advindas da nova conjuntura nacional. No mesmo sentido, os movimentos das comunidades de pesca saem do nível apenas reivindicatório para um nível mais operacional e propositivo. "Embora os eixos nucleadores das demandas fossem os mesmos, eles incorporam novas práticas" (GOHN, 2003, p.23). Sendo que os movimentos de pesca são, ao mesmo tempo, co-artíficies e vítimas dessa nova conjuntura nacional, como reafirmado pelas políticas neoliberais e efeitos da globalização. Fazendo assim com que os movimentos de pesca adotem um caráter difuso e com que as mudanças sejam, portanto, fontes de movimento. 
“Há na atualidade a existência de dois movimentos opostos, o da homogeneização e da heterogeneização dos espaços, culturas e histórias de maneira "universal'" (ZARUR, 2000, p.19), expresso no paradoxo de Baeta Neves Flores (1998), que consiste na seguinte frase: a ideologia do planetarismo vê-se, então, obrigada a lidar com uma situação 'prática' e 'objetiva' que apesar disso, é o signo de um paradoxo (o da existência vigorosa de 'partes' que se opõem ao triunfo hegemônico de um todo absoluto, símbolo do progresso e do devir). A questão do movimento das comunidades de pescadores e as empresas de pesca ilustra bem esse movimento de bipolarização de fins almejados. De um lado, encontram-se aqueles que se diferenciam de um todo para a busca de direitos a estes pertencentes e negados e do outro o todo hegemônico que busca a homogeneização dos espaços, culturas e unificação da história para o controle dos meios de produção.

Pode-se dizer então que a zona costeira do Brasil é palco da luta entre as ideologias de globalização "que se imaginam portadoras do futuro, do pragmatismo e da razão e ideologias da fundação, da região, da raiz, da origem, do passado, da origem e do sentimento" (ZARUR, 2000, p.22). Fomentadas assim pelo capitalismo e pelo aspecto atemporal e não continuo da globalização, assim como pela identidade cultural entre a população tradicional.

Como preconiza Golbery de Couto e Silva, é necessário que haja uma simbiose entre a política e a geopolítica, para que estas juntas, de forma gradual e sucessiva, consigam vencer seus confrontantes, "desenvolvendo uma estratégia de envolvimento (sucessiva e gradualmente abrangente)" (FREITAS, 2004, p.46) em que seu maior oponente é o próprio movimento social e a sua incapacidade em gerenciar o todo de forma eficaz para combater as empresas privadas e alcançar a figura do Estado.

O Movimento Nacional dos Pescadores, em si, teve início entre os anos de 1985 e 1987, quando pescadores de diferentes estados do país se juntaram para discutir a pesca no Brasil e propor a inclusão das reivindicações dos pescadores artesanais na então nova Constituição Brasileira (BRASIL, 1988). A esse movimento foi dado o nome de Constituinte da Pesca que em meados de 1989, passa a se denominar MONAPE.

A charneira litorânea brasileira necessitava de uma maior integração e interdependência como ponto de início para a busca organizada de direitos comuns. Movimento o qual culminou na construção, de maneira autônoma, da $1^{\circ}$ Conferência Nacional de Pesca Artesanal, em que:

Centenas de pescadores de vários estados brasileiros discutiram os rumos das políticas para a pesca e aqüicultura, sob o lema 'pescadores e pescadoras na luta por território, afirmando políticas de direito para a pesca artesanal'. (CALLOU, 2010, p.47).

O documento produzido pela I Conferência afirma que Seap/MPA está:

Privilegiando os interesses da aqüicultura empresarial e da pesca industrial, em detrimento da pesca artesanal. Afirma, ainda, que suas políticas estão voltadas para uma lógica de concentração de capital, emprego de tecnologias agressivas ao meio ambiente, desprezo e substituição da cultura tradicional. (SEAP, 2009). 
As reivindicações apresentadas no documento revelam, de um lado, a compreensão nítida que os povos do mar têm de sua situação socioambiental, cultural e política na atualidade e, de outro, informam o quanto se nega e o quanto ainda se está distante de reconhecer as culturas tradicionais pesqueiras como fonte de aprendizagem.

A impressão que fica, ao refazermos o caminho histórico dos povos do mar no Brasil, é de que as políticas públicas, em sua maioria passadas e contemporâneas, são indiferentes às reivindicações dos pescadores. Aos governos parece interessar apenas o conhecimento produzido no campo das tecnologias. Diga-se de passagem, daquelas tecnologias que podem promover a modernização e o desenvolvimento do setor pesqueiro e aquícola do empresariado nacional.

Mudanças e criações de órgãos responsáveis pelo assunto foram constantes, representando as mudanças de concepções dos governantes sobre o tema e atores envolvidos. Nesse sentido, um esforço para superar a invisibilidade das culturas tradicionais da pesca brasileira passa, irredutivelmente, pela esfera política. Como Habermas (1990) menciona, os movimentos são vistos, agora, como fatores dinâmicos na criação e expansão dos espaços públicos de discussão e emponderamento da sociedade civil.

Como um todo, pode-se dizer que: 1) há um baixo nível de organização dos atores de pesca (trabalhadores, empresários, armadores e comerciantes); 2) existem conflitos entre diversos segmentos das pescarias, sendo freqüentes aqueles entre a pesca artesanal e industrial que exploram o mesmo recurso e/ou ambiente; 3) há poucas iniciativas de autogestão independentes do Estado, bem sucedidas; e 4) há insuficiência e inadequação das políticas públicas para a gestão do setor pesqueiro. Em suma, "as medidas que foram adotadas não evitaram a sobre-exploração dos recursos, tendo sido, muitas vezes, apenas paliativas e de caráter assistencialistas e produtivistas, sem considerar os fatores limitantes da produção biológica e organização humana" (ISAAC et al, 2006, p.181).

\section{HISTÓRICO DO MOVIMENTO DAS COMUNIDADES TRADICIONAIS DE PESCA DO LITORAL CEARENSE}

A faixa litorânea do Ceará tem $573 \mathrm{~km}$ de extensão e nela existem atualmente mais de 100 comunidades pesqueiras que se distribuem em 20 municípios, algumas delas são Prainha do Canto Verde, Cumbe, Caetanos de Cima, Curral Velho e Assentamento Maceió. Essas comunidades, cuja formação remonta aos séculos XVIII e XIX, em sua maioria são marcadas pela descendência negra e indígena e recebem a denominação de comunidades pesqueiras, comunidades litorâneas, comunidades tradicionais ou de povos do mar.

Nas últimas décadas, as comunidades litorâneas se depararam com um processo de urbanização, industrialização e crescimento turístico desordenado que tem ameaçado sua subsistência, sua moradia e seu universo cultural. Essas transformações na costa cearense decorrem de uma política de desenvolvimento e crescimento econômico descomprometida com a sustentabilidade socioambiental da zona costeira e que exclui as 
comunidades tradicionais dos processos de discussão e decisão das políticas de desenvolvimento. O território aparece aqui como cenário das relações de poder entre os atores.

A história do movimento de comunidades tradicionais de pescadores no litoral cearense tem início em 1941 com o protesto contra o descaso das políticas de Vargas para com a pesca no estado. Já em 1985, várias entidades começaram a organizar os pescadores artesanais do Ceará para reivindicar melhores condições de trabalho, apoio à pesca artesanal e direitos humanos. Entre estas entidades se encontram: CPP (Conselho Pastoral dos Pescadores), MOPECE (Movimento dos Pescadores do Ceará) e MONAPE (Movimento Nacional dos Pescadores).

Com isso, o Movimento Nacional dos Pescadores (MONAPE) tem como papel principal promover uma melhor articulação dessas comunidades para que possam se posicionar concretamente frente seus interesses e assim ganhar mais espaço nas decisões políticas do Estado. Adota-se como método ações coletivas em busca de uma identidade única, enfatizando a identidade coletiva criada pelos grupos e não a identidade social criada por estruturas sociais, pois estes são capazes de se autodefinir e delimitar. Ressalta-se que "Pizzorno destaca que o processo de formação da identidade envolve demandas inegociáveis e que ocorre por meio da interação coletiva do grupo, interna e externa" (GOHN, 2003, p.131).

O MONAPE se divide em três outros movimentos mais específicos: o Fórum em Defesa da Zona Costeira do Ceará (FDZCC) - do qual fazem parte três grupos de trabalhos (GTs) (o GT de aqüicultura, o GT de pesca e o GT de turismo e gestão costeira) -, o Fórum dos Pescadores e Pescadoras do Litoral Cearense e a Rede Educação Ambiental do Litoral Cearense.

O Fórum em Defesa da Zona Costeira do Ceará reivindica a consolidação de modelos de desenvolvimento sustentável, de respeito à vida dos Povos do Mar, de preservação dos biomas costeiros em que vivem as comunidades litorâneas, de democratização dos espaços de discussão e decisão das políticas públicas para a pesca, para o uso e ocupação do solo e para o turismo, a participação das comunidades litorâneas no planejamento, monitoramento e avaliação das políticas governamentais de desenvolvimento. Com isso, o movimento reúne e agrupa diversos atores interessados nas suas causas.

O Fórum de Pescadores e Pescadoras do Litoral Cearense (FPPLC) reúne grupos na luta pela melhoria da qualidade de vida dos pescadores. Uma das necessidades da criação do movimento foi justamente a organização e articulação dessas populações costeiras, formadas por pescadores, pescadoras e suas famílias, para que possam se mobilizar e garantir seus direitos de posse sobre a terra em que vivem. Seus principais objetivos são combater a pesca predatória e buscar uma atividade pesqueira sustentável; propor políticas públicas para a pesca artesanal; combater a especulação imobiliária e defender o direito à terra dos povos do mar; proporcionar educação e cidadania para as comunidades litorâneas e promover a capacitação para formação de lideranças periodicamente.

A Rede de Educação Ambiental do Litoral Cearense assume espaço vital nas escolas, associações comunitárias, colônias de pescadores e nas iniciativas turísticas do litoral cearense de modo a garantir a vida e a sobrevivência das populações costeiras que estão 
intimamente ligadas à preservação dos ecossistemas. A Rede articula as comunidades litorâneas e busca fortalecer os processos educativos, de autogestão, de autonomia e de sustentabilidade dessas populações na perspectiva da conservação dos recursos naturais e do patrimônio material e imaterial dos povos do mar.

Desta maneira, o MONAPE articula todas as comunidades tradicionais pesqueiras do litoral cearense para que sejam mais coesas em suas reivindicações e na participação das decisões tomadas na região. Empregando assim a participação cidadã, "desvinculada de deveres permanentes para com a organização, sendo a mobilização efetuada independentemente de laços anteriores de pertencimento" (GOHN, 2003, p.18). Sendo então a sociedade civil organizada uma parceira permanente desta, deixando de ser coadjuvante para se tornar ativa.

Em 1985, há o começo dos embates entre os pescadores tradicionais e as empresas, conglomerados comerciais da pesca da lagosta e pescado, resultando em vários protestos e mortes. Um dos protestos mais importantes foi o de 1995, resultado da queda de cerca de $50 \%$ no número de exportação de lagostas, devido à pesca agressiva e desenfreada ocorrida nos últimos anos, "mesmo sendo a pesca artesanal responsável por $96,3 \%$ de sua captura, o que torna a frota dessa região a menos industrializada do país" (CASTELLO, 2010, p.33).

Nesta manifestação, cerca de 500 pescadores e mulheres, acompanhados do Superintendente do IBAMA, protestaram em frente à sede do Governo do Estado e entregaram a «Carta da Prainha do Canto Verde», um documento pedindo medidas que assegurem a preservação do litoral cearense ao representante do Governador. Como reação, houve a primeira reunião do setor pesqueiro como um todo para avaliar o problema. É criado, então, o que hoje é conhecido como COMPESCE - Comitê de Pesca do Estado do Ceará. Em âmbito nacional temos em pouco tempo a criação do Comitê de Pesca, que apresenta o primeiro Plano de Ordenamento para a pesca da lagosta do Ceará (POPL) ao IBAMA, advindo de uma petição formal do órgão estadual ao governo federal.

Nos anos que se seguem, o COMPESCE ganha mais status regionalmente e os prefeitos dos municípios costeiros são formalmente convidados a fazerem parte do mesmo. Concomitantemente, o FDZCC, que nasceu na informalidade de uma assembleia, continua a crescer em quantidade e qualidade, com isso aumentando a pressão sobre o governo do estado e o Ibama para que a implementação dos projetos seja levada adiante, contando também com a ajuda da imprensa local. Adquiriu-se assim um caráter consultivo e integrante permanente do comitê em questão, participando da etapa de "decisão de reconstruir integralmente o território de acordo com as necessidades do poder" (DEBORD, 1967, p.118). Poder este que é parte intrínseca de toda relação. Multidimensionalidade e imanência do poder em oposição à unidimensionalidade e à transcendência: "O poder está em todo lugar; não que englobe tudo, mas vem de todos os lugares" (RAFFESTIN, 1993, p.18).

A atuação do movimento das comunidades tradicionais de pesca do litoral cearense culmina na participação deste na $1^{\text {a }}$ Conferência de Pesca Artesanal do Brasil, ocorrida em Brasília, em que movimentos de vários estados brasileiros se reúnem para discutirem 
as problemáticas e papéis a serem assumidos por estes de forma coordenada em âmbito nacional.

\section{RELAÇÕES DE PODER NO ÂMBITO DO LITORAL CEARENSE: REIVINDICAÇÕES E CONQUISTAS}

Um ponto fundamental na análise dos movimentos sociais, e não é diferente no caso do movimento dos pescadores cearenses, é a percepção de que todos eles estão envoltos em relações de poder, tanto sociais como políticas, mesmo porque: "a luta pelo poder é um elemento intrínseco na relação entre os homens" (COSTA, 1992, p.173). Neste sentido, as comunidades pesqueiras estão sempre em um embate de poder contra o meio privado - principalmente contra as grandes empresas pesqueiras que dominam o mercado de pescados - e também contra o Estado, para conseguirem que suas reivindicações sejam alcançadas. Contudo, os pescadores também estão cientes da sua fragilidade diante das companhias de pesca que têm conhecimento da sua posição privilegiada como detentoras de poder econômico, o que muita das vezes as possibilita de ter o respaldo do Estado.

Apesar disso, os povos que vivem da pesca não permanecem apáticos frente a tal situação. Os pescadores se organizaram em associações e fóruns para fazer pressão no Estado e na sociedade como um todo, tanto por meio de manifestações populares quanto pelo voto, para que suas reivindicações sejam alcançadas. Essas comunidades ainda contam com apoio de outras organizações, como as ONGs de preservação do desenvolvimento sustentável, formando, assim, redes de informação e cooperação que têm o objetivo de fortalecer o movimento. Essa criação de alianças é fundamental para a obtenção de vitórias nas questões de conflitos de poder e na participação da formulação de políticas públicas favoráveis (COSTA, 1992), pois quanto mais o movimento consegue se articular com outros agentes da sociedade civil - através, principalmente, da "ação comunicativa" e da "ação política vigorosa" - mais visibilidade e alcance ele terá.

A principal reivindicação dos pescadores do Ceará está relacionada à pesca predatória da lagosta, já que esse crustáceo representa a maior fonte de renda das comunidades locais. Entretanto, existem outras demandas importantes, como o fim da carcinicultura (criação de camarões em grandes viveiros); a necessidade do turismo sustentável na região litorânea e a não utilização da costa para grandes empreendimentos imobiliários. Com relação à lagosta, os povos pesqueiros afirmam que a pesca feita pelas grandes empresas é excessiva, o que é bastante prejudicial à atividade pesqueira em si, pois reduz a quantidade do crustáceo no mar, principalmente se feita durante período reprodutivo. Neste contexto, é importante frisar que a não possibilidade da pesca significa não só a falta de ganho econômico para as populações litorâneas tradicionais, como também representa a destruição de um modo de vida, de uma cultura e de uma identidade. Neste sentido, a organização dos pequenos pescadores em um movimento também serve para preservar a identidade cultural e coletiva das comunidades do litoral, que é característica central dos NMS e não pode ser deixada de lado (GOHN, 2000). 
Apesar de toda essa argumentação das populações pesqueiras, as grandes empresas pesqueiras alegam que têm autonomia no mar aberto, que seria longe da área de pesca das comunidades locais, o que não prejudicaria a pesca à vela. Afirmam também que têm o direito comercial da pesca tanto quanto os pequenos pescadores e não podem ser impedidos de exercer essa atividade ${ }^{2}$. Assim, os empresários conseguem se manter no litoral e fazer concorrência ao trabalho dos pescadores locais.

Deste modo, a luta das comunidades pesqueiras se concentra, em grande parte, na tentativa da criação de medidas institucionais que reprimam a pesca predatória. Suas reivindicações são feitas frente ao Estado, pois os pescadores partem do princípio que é ele quem detém o papel de harmonizar as questões sociais, políticas e econômicas expressadas pela opinião pública dentro do seu território. Entretanto, uma grande dificuldade encontrada pelas comunidades de pescadores na busca pela preservação da pesca artesanal está no lobby feito pelas grandes empresas privadas frente aos governos locais e nacional. Como a lagosta é um dos principais produtos de exportação do litoral cearense, as grandes empresas pesqueiras acabam conseguindo controlar, de certa forma, as pautas de discussões ecológicas, econômicas e sociais da região e mesmo do país. Essas companhias, muitas vezes, visando somente seus interesses financeiros e sendo detentoras do poder econômico, não se preocupam com questões ambientais e socioculturais - a pesca predatória da lagosta em detrimento da pesca artesanal é um exemplo disso - e acabam, muita vezes, por conseguir que políticas relacionadas a essas áreas não sejam formuladas.

Todavia, essa situação vem passando por alguns processos de mudanças que favorecem as comunidades tradicionais, mudanças essas que são o reflexo direto da atuação organizada do movimento. Uma grande conquista obtida pelos pescadores locais será a implementação de aparelhos eletrônicos, pelo Instituto de Tecnologia da Informação e Comunicação (ITIC) com o apoio do Ministério da Pesca e da Aquicultura, para o monitoramento da pesca predatória da lagosta durante a cadeia reprodutiva do crustáceo ${ }^{3}$. Há também o projeto do governo federal de gestão compartilhada que vem possibilitando a participação nas tomadas de decisão dos atores diretamente envolvidos na questão. Deste modo, foram criados em níveis estadual e nacional os Comitês de Gestão de Uso Sustentável da Lagosta incluindo, além dos empresários e governos que tradicionalmente decidiam sobre as políticas neste campo, representantes dos pescadores e da sociedade civil ${ }^{4}$. Isso mostra que a confrontação política feita pelos movimentos sociais lhes permite atingir, se não todas, parte de suas reivindicações.

Neste contexto, são percebidas as dificuldades enfrentadas pelos pescadores tradicionais do litoral cearense, uma vez que eles travam conflitos com os grandes detentores do poder político como o Estado, e de poder econômico como as grandes companhias pesqueiras privadas. Contudo, através de uma ação social - redes de trocas de informação, manifestações populares e atuação junto à mídia - e também ação política

2 Disponível em: < http://www.portaldomar.org.br> Acesso em: 28 nov. 2011.

3 Disponível em: <http://www.valoronline.com.br/?impresso/gestao_da_incerteza_3_parte/321/6336009/pesca-de-lagosta-tera-controle-eletronico> Acesso em: 28 nov. 2011.

4 Disponível em: < http://www.portaldomar.org.br/oktiva.net/1275/nota/155428> 28 nov. 2011. 
- participação na formulação de políticas e por meio do voto - presentes e firmes, o movimento dos pescadores está conseguindo atingir alguns dos seus principais objetivos. Neste sentido, é notável como as relações de poder estão se dilatando aos mais diferentes atores dentro das sociedades contemporâneas cada dia mais globalizadas.

\section{CONSIDERAÇÕES FINAIS}

No âmbito de uma análise geopolítica contemporânea, foram abordadas no presente artigo as questões territoriais, os atores sociais e a relação de poder existente entre o MONAPE e as políticas de Estado para o ordenamento territorial e dos recursos pesqueiros.

Deste modo, nota-se o esforço de articulação entre as comunidades de pescadores no intuito de pressionar o poder público para que suas reivindicações e direitos sejam atendidos, e ainda, para que se tornem voz ativa dentro das tomadas de decisão que dizem respeito à zona litorânea e à atividade de pesca.

Desse modo, mostra-se necessária uma coesão do segmento para se tornar ator social mais ativo nas relações de poder, onde existem jogos de interesses diversos e formas de apropriação territorial variadas. O MONAPE se apresenta como representante de um modo de vida rico em relações socioculturais e que detêm certo poder de resistência contra a expansão do modo de produção privado capitalista que é hegemônico no planeta atualmente.

\section{REFERÊNCIAS}

BACKHEUSER, E. Leis geopolíticas da evolução dos Estados. Rio de Janeiro: Boletim Geográfico, n. 88, IBGE, 1950.

BRASIL. Constituição Federal. Brasília: 1988.

BRASIL. Lei n. 8617 de 04 de janeiro de 1993. Dispõe sobre o mar territorial, a zona contigua, a zona econômica exclusiva e a plataforma continental brasileiros e da outras providencias. Disponível em: <http://www.planalto.gov.br/ccivil_03/Leis/L8617.htm>. Acesso em: 28 nov. 2011.

CARDOSO, E. Geografia e pesca: aportes para um modelo de gestão. Revista do Departamento de Geografia da USP, v.1, n.14, p.79-88, jan, 2001.

CASTELLO, J. P. O futuro da pesca e da aqüicultura marinha no Brasil: A pesca costeira. Ciência e Cultura, v.1, n.3, 2010.

CALLOU, A. Povos do Mar: Herança sociocultural e perspectivas no Brasil. Ciência e Cultura, v.62, n. 3, 2010.

COSTA, W. M. Geografia política e geopolítica. São Paulo: Hucitec, 1992.

DEBORD, G. A sociedade do espetáculo. Rio de Janeiro: Contraponto, 1967.

DIEGUES, A. C. S. Povos e mares: uma retrospectiva de socioantropologia marítima. São Paulo: Nupaub, n. 9 (Série Documentos e Relatório de Pesquisa), 1993.

FLORES, L. F. B. N. A construção do discurso científico. Rio de Janeiro: UERJ, 1998.

FREITAS, J. A escola geopolítica Brasileira. Rio de Janeiro: Biblioteca do Exército, 2004. 
GOHN, M. da G. Teoria dos movimentos sociais. São Paulo: Loyola, 2000.

2003.

Movimentos sociais no início do século XXI: antigos e novos atores sociais. Petrópolis: Vozes,

HABERMAS, J. Communication and the Evolution of the Society. Policy Press. Cambridge, 1976.

The theory of communicative action: reason and racionalization of the society. Cambridge: Policy Press, 1981. v. 1.

"Neues Vorwort" [Novo prefácio]. In: HABERMAS, Jurgen. Strukturwandel der Öffentlichkeit [Mudança estrutural da esfera pública]. Frankfurt a.M.: Suhrkamp,1990.

HAESBAERT, R. Dos múltiplos territórios a multiterritorialidade. Porto Alegre: 2004.

ISAAC, V; MARTIS, A. S.; HAIMOVICI, M.; CASTELLO, J. P.; ANDRIUETTO, J. M. Síntese do estado de conhecimento sobre a pesca marinha e estuarina do Brasil. Belém: UFPA, 2006.

MACKINDER, H. The geographical pivot of history. The Geographical Journal, 23, p. 421-37,1904. Disponível em : <http://www.britannica.com/EBchecked/topic/229628/The-Geographical-Pivot-ofHistory>. Acesso em: 28 nov. 2011.

MAHAN, A. T. Mahan on naval strategy: selections from the writings of rear admiral Alfred Thayer Mahan. Annapolis, MD: Naval Institute Press, 1991.

MICHILES, C. Ciência e política sob a perspectiva do realismo utópico. Brasília: EdUnB, 2003.

MUSSOLINE, G. Aspectos da cultura e da vida social no litoral brasileiro. In: SCHADEN, Egon. Homem, cultura e sociedade no Brasil. Petrópolis: Vozes, 1972.

OLIVEIRA, R. O panorama da aqüicultura no Brasil: a prática com foco na sustentabilidade. Revista Intertox de Toxicologia, Risco Ambiental e Sociedade, v. 2, n. 1, p. 71-89, fev. 2009.

PAIVA, M. P .; PAIVA, M. A. P. Situação econômica-social dos pescadores artesanais do Ceará. Boletim da Sociedade Cearense de Agronomia. Fortaleza, v. 8. 1967.

RAFFESTIN, C. Por uma geografia do poder. São Paulo: Ática, 1993.

SEAP. I Conferência da Pesca Artesanal no Brasil. Brasília: Texto base, 2009.

SUDEPE. I Plano nacional de Pesca. Sudepe: Brasília, 1963.

VIANNA, L. P. De invisíveis a protagonistas: populações tradicionais e unidades de conservação. São Paulo: Annablume; FAPESP, 2008.

ZARUR, G. de C. L. (Org.). Região e nação na América Latina. Brasília/ São Paulo: EdUnB e Imprensa Oficial do Estado, 2000.

Recebido em 30/11/2011

Aceito para publicação em 09/02/12 